\title{
Thermal conductivity and viscosity of Al2O3 nanofluids for different based ratio of water and ethylene glycol mixture
}

\begin{abstract}
In the thermal engineering applications, suspension of nanoparticles in conventional fluid has positive potential in enhancing the convective heat transfer performance. The evaluation of thermo-physical properties is essential to investigate the forced convection heat transfer of nanofluids. Hence, the present study reports the analysis on thermal conductivity and dynamic viscosity for $\mathrm{A} 12 \mathrm{O} 3$ nanoparticle dispersed in a different volume ratio of water (W) and ethylene glycol (EG) mixture. The $\mathrm{Al} 2 \mathrm{O} 3$ nanofluids are formulated using the two-step method for three different base mixtures with volume ratio of 40:60, 50:50 and 60:40 (W:EG). The measurement of thermal conductivity and viscosity were performed using KD2 Pro Thermal Properties Analyzer and Brookfield LVDV-III Rheometer; respectively for temperature from 30 to $70{ }^{\circ} \mathrm{C}$ and volume concentration of $0.2-1.0 \%$. The average thermal conductivity enhancement of $\mathrm{A} 12 \mathrm{O} 3$ nanofluids in the three base ratios varied from 2.6 to 12.8\%. The nanofluids have better enhancement as the percentage of ethylene glycol increases. Meanwhile, the average dynamic viscosity enhanced up to 50\% for 60:40 (W:EG). The enhancement of viscosity for nanofluids decreased with the increment percentage of ethylene glycol. The properties enhancement of the $\mathrm{Al} 2 \mathrm{O} 3$ nanofluids is significantly influenced by the concentration, temperature, and based ratio.
\end{abstract}

Keyword: Thermal conductivity; Viscosity; Nanofluids; Water-ethylene glycol mixture; Based ratio 